Article

\title{
Catalase-Like Antioxidant Activity is Unaltered in Hypochlorous Acid Oxidized Horse Heart Myoglobin
}

\author{
Gulfam Ahmad ${ }^{1}$, Belal Chami ${ }^{2}$, Mary El Kazzi ${ }^{1}$, Xiaosuo Wang ${ }^{1}$, Maria Tereza S. Moreira ${ }^{1}$, \\ Natasha Hamilton ${ }^{1}$, Aung Min Maw ${ }^{1}$, Thomas W. Hambly ${ }^{1}$ and Paul K. Witting ${ }^{1, *(D)}$ \\ 1 Redox Biology Group, Discipline of Pathology, Faculty of Medicine and Health, Charles Perkins Centre, \\ The University of Sydney, Sydney, NSW 2006, Australia; gulfam.ahmad@sydney.edu.au (G.A.); \\ mael2199@uni.sydney.edu.au (M.E.K.); xiaosuo.wang@sydney.edu.au (X.W.); \\ mariatereza.sm@gmail.com (M.T.S.M.); natasha.hamilton@sydney.edu.au (N.H.); \\ amaw2321@uni.sydney.edu.au (A.M.M.); t.hambly@gmail.com (T.W.H.) \\ 2 Discipline of Oral Pathology, Faculty of Medicine and Health, Charles Perkins Centre, \\ The University of Sydney, Sydney, NSW 2006, Australia; belal.chami@sydney.edu.au \\ * Correspondence: paul.witting@sydney.edu.au
}

Received: 27 June 2019; Accepted: 16 September 2019; Published: 18 September 2019

\begin{abstract}
Activated neutrophils release myeloperoxidase that produces the potent oxidant hypochlorous acid $(\mathrm{HOCl})$. Exposure of the oxygen transport protein horse heart myoglobin $(\mathrm{hhMb})$ to $\mathrm{HOCl}$ inhibits Iron III (Fe(III))-heme reduction by cytochrome $b 5$ to oxygen-binding Iron II (Fe(II))Mb. Pathological concentrations of $\mathrm{HOCl}$ yielded myoglobin oxidation products of increased electrophoretic mobility and markedly different UV/Vis absorbance. Mass analysis indicated $\mathrm{HOCl}$ caused successive mass increases of 16 a.m.u., consistent serial addition of molecular oxygen to the protein. By contrast, parallel analysis of protein chlorination by quantitative mass spectrometry revealed a comparatively minor increase in the 3-chlorotyrosine/tyrosine ratio. Pre-treatment of hhMb with $\mathrm{HOCl}$ affected the peroxidase reaction between the hemoprotein and $\mathrm{H}_{2} \mathrm{O}_{2}$ as judged by a $\mathrm{HOCl}$ dose-dependent decrease in spin-trapped tyrosyl radical detected by electron paramagnetic resonance (EPR) spectroscopy and the rate constant of 2,2'-azino-bis(3-ethylbenzothiazoline-6-sulphonic acid (ABTS) oxidation. By contrast, $\mathrm{Mb}$ catalase-like antioxidant activity remained unchanged under the same conditions. Notably, $\mathrm{HOCl}$-modification of $\mathrm{Mb}$ decreased the rate of ferric-to-ferrous $\mathrm{Mb}$ reduction by a cytochrome b5 reductase system. Taken together, these data indicate oxidizing $\mathrm{HOCl}$ promotes $\mathrm{Mb}$ oxidation but not chlorination and that oxidized $\mathrm{Mb}$ shows altered $\mathrm{Mb}$ peroxidase-like activity and diminished rates of one-electron reduction by cytochrome b5 reductase, possibly affecting oxygen storage and transport however, Mb-catalase-like antioxidant activity remains unchanged.
\end{abstract}

Keywords: myoglobin; hypochlorous acid; protein oxidation; haem-iron reduction; MetMb reductase; catalase-like antioxidant activity

\section{Introduction}

Neutrophils are recruited to heart tissues after acute myocardial infarction (AMI); recruitment occurs within the first $24 \mathrm{~h}$ as part of the early innate inflammatory response post AMI [1,2]. Activated neutrophils release myeloperoxidase (MPO) that produces the potent oxidant hypochlorous acid ( $\mathrm{HOCl}$ ), which is cell permeable and known to cause oxidative modification of proteins and low-molecular weight biomolecules [3,4]. In the case of proteins, oxidizing $\mathrm{HOCl}$ reacts most rapidly with sulfur containing residues such as cysteine and methionine, followed by protein-side chains containing lysine, histidine, tryptophan and tyrosine $[5,6]$. Intact proteins become oxidized at these reactive amino centers to yield oxidized and/or chlorinated products (e.g., for tyrosine dimeric, hydroxylated or chlorinated products can be formed largely dependent on the oxidant involved). 
The oxygen transport protein myoglobin $(\mathrm{Mb})$ is a predominant protein in skeletal and cardiac muscle [7]. Therefore, $\mathrm{Mb}$ is potentially a primary target for oxidizing $\mathrm{HOCl}$ produced by neutrophils recruited to the myocardium following a heart attack, potentially leading to a secondary oxidative process that may further inhibit cardiac function post-AMI [8]. The primary function of $\mathrm{Mb}$ in muscle cells is generally considered as an oxygen transport/storage protein [9] although its role in the maintenance and regulation of redox active molecules such as hydrogen peroxide $\left(\mathrm{H}_{2} \mathrm{O}_{2}\right)$ and nitric oxide (NO) are other important functions for this protein. In the case of $\mathrm{NO}, \mathrm{Mb}$ can diminish the concentration of this vasoactive molecule through oxidation $[10,11]$ and/or increase NO concentrating through $\mathrm{Mb}^{\prime}$ s inherent nitrite reductase activity [12]. In particular, the ability of $\mathrm{Mb}$ to act as a nitrite reductase has been linked to regulation of muscle contractile function [13]. Furthermore, cardiac $\mathrm{Mb}$ is also a pseudo-peroxidase that also exhibits a catalase-like antioxidant activity [14]; both enzymic activities may be important in regulating levels of cardiac hydrogen peroxide $\left(\mathrm{H}_{2} \mathrm{O}_{2}\right)$ particularly following acute ischemia-reperfusion injury post AMI.

Here we identify that $\mathrm{Mb}$ oxidation by reagent $\mathrm{HOCl}$ decreases the efficiency of the one-electron reduction between ferric $\mathrm{Mb}[\mathrm{MbFe}(\mathrm{III})]$ by a cytochrome $b 5$ reductase system (considered to represent the intracellular $\mathrm{Mb}$ reductase necessary to maintain the ferrous $\mathrm{Mb}(\mathrm{MbFe}(\mathrm{II})$ ) form. Changes to the maintenance of intracellular $\mathrm{MbFe}(\mathrm{II})$ potentially impacts on oxygen-binding/transport to mitochondria for oxidative phosphorylation and cellular energetics.

\section{Material and Methods}

\subsection{Materials}

Purified cytochrome $b 5$ and human NADPH-P450 reductase were purchased from Invitrogen (Sydney, Australia). These two proteins are central to the intracellular Mb-reductase system [15]. All buffers were prepared using Nanopure filtered water followed by storage over Chelex-100 ${ }^{\circledR}$ resin (BioRad, Sydney, Australia) at $4{ }^{\circ} \mathrm{C}$ for at least $24 \mathrm{~h}$ to remove contaminating transition metal ions. Solutions of stock $\mathrm{HOCl}$ (Merck, Sydney, Australia) were standardized by using $\mathrm{A}_{292 \mathrm{~nm}}$ $\left({ }^{-} \mathrm{OCl}\right)=350 \mathrm{M}^{-1} \mathrm{~cm}^{-1}$ and $\mathrm{A}_{235 \mathrm{~nm}}(\mathrm{HOCl})=100 \mathrm{M}^{-1} \mathrm{~cm}^{-1}$ [16]. The stock was diluted into phosphate buffered saline (PBS, $250 \mathrm{mM}$, pH 7.4) prior to use. Horse heart Mb (hhMb) was obtained from Sigma Aldrich (Sydney, Australia) and stock solutions of this protein were prepared immediately before use in $250 \mathrm{mM}$ PBS (pH 7.4) and standardized using $409=188,500 \mathrm{M}^{-1} \mathrm{~cm}^{-1}$ [17]. This concentration of phosphate buffer was selected to avoid alterations in $\mathrm{pH}$ upon addition of reagent $\mathrm{HOCl}$ as increased $\mathrm{pH}$ may interfere with the reaction between the oxidant and $\mathrm{hhMb}$. Unless specified otherwise, all other chemicals employed were analytical grade reagents.

\subsection{Experimental Section}

\subsubsection{Oxidation Reactions}

All oxidation reactions were carried out at $37^{\circ} \mathrm{C}$ in $250 \mathrm{mM}$ PBS (pH 7.4) containing hhMb at the final concentrations indicated in the legends to the figures. The buffer concentration employed here was used to decrease the possibility that added $\mathrm{HOCl}$ altered the $\mathrm{pH}$ of the reaction mixture upon addition to $\mathrm{hhMb}$, which may affect the tertiary structure and hence availability of amino acids to interact with the oxidizing reagent $\mathrm{HOCl}$. All reagents and protein solutions were freshly prepared, and reactions were initiated by addition of reagent $\mathrm{HOCl}$ (ranging $0-50 \mathrm{~mol} / \mathrm{mol}$ excess of the oxidant relative to $\mathrm{hhMb}$ ) or water (as vehicle control) to the protein with rapid mixing. This in vitro system was designed to model the reaction of cardiac $\mathrm{Mb}$ in the presence of activated leukocytes that release extracellular MPO, the enzyme responsible for generating oxidizing $\mathrm{HOCl}$. Oxidized proteins were prepared immediately prior to use in the designated analytical studies. Final $\mathrm{HOCl} / \mathrm{hhMb}(\mathrm{mol} / \mathrm{mol})$ ratios were as specified in the legends to the figures. A dose range of $\mathrm{HOCl} / \mathrm{hhMb}$ ratios was tested here since the precise concentration of $\mathrm{HOCl}$ produced by leukocytes recruited to an area of inflammation 
is not clear. Whether the dose range employed is pathophysiologically relevant in vivo is somewhat dependent on the level of leukocyte recruitment to an inflammatory region of tissue, the degree of cellular activation to promote degranulation and activation of extracellular MPO and the prevalence of biological targets in the local region of the organ investigated (i.e., here we targeted $\mathrm{Mb}$ that is present at a relatively high concentration in myocardial muscle).

\subsubsection{Electrophoretic Mobility of Native and HOCl-Modified hhMb}

The electrophoretic mobility of native and $\mathrm{HOCl}$-modified hhMb was determined by using a protocol originally established to monitor oxidation status of low-density lipoprotein [18]. Briefly, electrophoresis was performed with an agarose gel $(0.8 \%$ agarose in TAE buffer) and staining with Coomassie Brilliant Blue R-250 to highlight protein migration. Electrophoresis was performed at $100 \mathrm{~V}$ over a period of $30 \mathrm{~min}$ and the relative electrophoretic mobility (REM) was defined as the relative distance migrated from the origin by $\mathrm{HOCl}$-oxidized hhMb compared to the native hhMb in the absence of $\mathrm{HOCl}$ (control) with the cathode (-) placed at the top of the gel closest to the loading comb and the anode $(+)$ at the bottom.

\subsubsection{UV-Vis Absorbance Spectroscopy}

Steady state visible spectra of native and oxidized hhMb were accumulated using a Beckman Coulter DU800 UV/Vis Spectrophotometer (Beckman Coulter Australia Pty Ltd, Sydney, Australia) maintained at $25 \pm 0.1^{\circ} \mathrm{C}$ with a Peltier temperature controller (Beckman Coulter Australia Pty Ltd, Sydney, Australia). To assess changes to baseline spectral characteristics, solutions of hhMb (ranging up to $50 \mu \mathrm{M}$ ) were treated with increasing doses of $\mathrm{HOCl}$ (final mole ratio ranging $0.5-50 \mathrm{~mol} / \mathrm{mol}$ ) and immediately transferred to a $1 \mathrm{~mL}$ quartz cuvette for spectral analysis in the range 500-600 nm). To conduct peroxidase activity measurements through the monitoring of rates of substrate oxidation in the presence of hhMb, a stock solution of 2,2'-azino-di-(3-ethyl)benzthiazoline-6-sulfonic acid (ABTS) was freshly prepared containing: $5 \mathrm{mM} \mathrm{ABTS}$ and $50 \mu \mathrm{M} \mathrm{H}_{2} \mathrm{O}_{2}$ in $0.1 \mathrm{M}$ potassium phosphate buffer (pH 7.0). The substrate stock solution was placed into a $1 \mathrm{~mL}$ volume quartz cuvette (path length: $1 \mathrm{~cm}$ ) and $\mathrm{hhMb}$ (final concentration $10 \mu \mathrm{M}$ ) was added to the mixture and the time-dependent accumulation of the ABTS radical cation was monitored at $\mathrm{A}_{734 \mathrm{~nm}}$ using a Beckman Coulter DU800 $\mathrm{UV} /$ Vis Spectrophotometer maintained at $25 \pm 0.1^{\circ} \mathrm{C}$ with an automated Peltier temperature controller. All pseudo first-order rate constants were determined as linear time dependent change in $A_{734} \mathrm{~nm}$ averaged over at least three independent rate determinations for each concentration of $\mathrm{HOCl}$ tested.

\subsubsection{Assessment of 3-Chlorotyrosine (3-Cl-Tyr)}

The biomarker for $\mathrm{HOCl}$ oxidation of tyrosine (3-Cl-Tyr) was assessed by quantitative liquid chromatography with tandem mass spectrometry (LC-MS/MS) as described previously [19,20]. Briefly, $100 \mu \mathrm{g}$ of (native or $\mathrm{HOCl}-$ modified) hhMb was precipitated in $3 \% w / v$ sodium deoxycholate and $50 \%$ $w / v$ trichloroacetic acid $/ \mathrm{H}_{2} \mathrm{O}$, followed by centrifugation $(6000 \times g, 5 \mathrm{~min})$ to pellet the solid protein. Protein pellets were washed in ice-cold acetone $(2 \times 0.5 \mathrm{~mL})$ and then dried under a stream of $\mathrm{N}_{2(\mathrm{~g})}$ before adding $6 \mathrm{M}$ methane sulfonic acid. The acidified mixture was finally hydrolyzed under vacuum $\left(110^{\circ} \mathrm{C}\right)$ and after $\sim 18 \mathrm{~h}$, the dark hydrolysate was resuspended in Nanopure water and purified using solid phase extraction cartridges (Superclean Envi-Chrom, 250 mg, Sigma-Aldrich, Sydney, Australia). Detection and quantification of 3-Cl-Tyr, unmodified tyrosine and corresponding labeled internal standards in these purified hydrolysates was conducted using an Agilent 6460 triple quad mass spectrometer (Agilent Technologies Australia Pty Ltd, Mulgrave Victoria, Australia) coupled with 1290 LC series (Agilent Technologies Australia Pty Ltd, Mulgrave Victoria, Australia) as described previously [20]. 


\subsubsection{Liquid Chromatography and Electrospray Mass Spectrometry}

Final reaction mixtures were diluted in MilliQ Water to yield $\sim 1 \mu \mathrm{M}$ protein and then aspirated and desalted using a ZipTip cartridge (Merck-Millipore, Sydney Australia) to bind, wash and elute the purified protein. Purified proteins were then subjected to two procedures as outlined below:

1. Proteins were separated at a flow rate of $0.4 \mathrm{~mL} / \mathrm{min}$ on a $\mathrm{C} 18$ reverse-phase column (particle size $3 \mu \mathrm{m}, 3 \mathrm{~mm} \times 150 \mathrm{~mm})$ using solvent A $(0.1 \% v / v$ trifluoroacetic acid in water $)$ and solvent $\mathrm{B}$ $\left(0.1 \% \mathrm{v} / \mathrm{v}\right.$ trifluoroacetic acid in $\left.\mathrm{CH}_{3} \mathrm{CN}\right)$ and products were detected by absorbance at $210 \mathrm{~nm}$ to assess the impact of $\mathrm{HOCl}$-oxidation on $\mathrm{hhMb}$ (as measured by changes in retention time for modified protein(s) eluting from the column).

2. Where required, mass analyses were performed on desalted protein samples (Ziptips Cat\# Z720070); Merck-Millipore in positive ion mode with a Finnigan LCQ Deca XP ion trap instrument (Thermo Fisher Scientific, San Jose, CA, USA) coupled to a Finnigan Surveyor HPLC system (Thermo Fisher Scientific, San Jose, CA, USA) as described in detail elsewhere [21]. Modified $\mathrm{hhMb}$ proteins were injected directly to the electrospray MS under the following parameters: Electrospray needle was held at $4500 \mathrm{~V}$; sheath gas was nitrogen set at 80 units; collision gas was helium and the temperature of the heated capillary was $250{ }^{\circ} \mathrm{C}$. This analytical approach consistently resulted in detection of the apo-protein without the haem moiety as the haem group is non-covalently bound to the protein.

\subsubsection{Electron Paramagnetic Resonance and Spin Trapping Studies}

Standard X-band electron paramagnetic resonance (EPR) spectra were obtained at $22{ }^{\circ} \mathrm{C}$ with a Bruker EMX Benchtop spectrometer (Bruker Pty Ltd, Preston, Victoria, Australia) as described previously [22]. Separate solutions of native or $\mathrm{HOCl}$-oxidized hhMb $(0.5 \mathrm{mM})$ were treated with $\mathrm{H}_{2} \mathrm{O}_{2}$ (ratio $\mathrm{H}_{2} \mathrm{O}_{2}: \mathrm{hhMb} \sim 5 \mathrm{~mol} / \mathrm{mol}$ ) in the presence or absence of activated charcoal-purified spin trap [23] 5,5-dimethyl-1-pyrroline N-oxide (DMPO; Sigma-Aldrich, Sydney Australia; final concentration $5 \mathrm{mM}$ ). Next, a sample of the reaction mixture $(250 \mu \mathrm{L})$ was removed and rapidly transferred into a standard quartz flat cell (Wilmad, Buena, NJ, USA) for EPR analyses at $22{ }^{\circ} \mathrm{C}$. The limit of detection of a stable nitroxide (TEMPO) measured under identical conditions was determined to be $\sim 50 \mathrm{nM}$. EPR spectra were obtained as an average of five cumulative scans with a modulation frequency of $100 \mathrm{kHz}$ and a sweep time of $84 \mathrm{~s}$. Microwave power and modulation amplitude used for each analysis varied appropriately as indicated in the figure legends. The metal chelator diethylenetriaminepentaacetic acid (DTPA, final concentration $100 \mu \mathrm{M}$ ) was included in reaction mixtures to minimize the possibility of peroxide decomposition by Fenton-type chemistry.

\subsubsection{Mb Catalase-Like Activity}

Assessment of hhMb catalase activity was determined monitoring the reaction between $\mathrm{hhMb}$ and two peroxide sources; $\mathrm{H}_{2} \mathrm{O}_{2}(30 \% \mathrm{v} / \mathrm{v})$ or cumene hydroperoxide $(99.6 \%$ purity) were from Sigma-Aldrich (Sydney, Australia). Working solutions of peroxide (final concentration $200 \mu \mathrm{M}$ ) were mixed with native or $\mathrm{HOCl}$-modified $\mathrm{hhMb}$ (final concentration) loss of peroxide was examined after $15 \mathrm{~min}$ reaction at $22^{\circ} \mathrm{C}$, where the residual levels of peroxide were determined using a modified Ferrous Oxidation-Xylenol Orange (FOX)-1 assay as described in detail elsewhere [24]. Briefly, an aliquot of ( $250 \mu \mathrm{M}$ ammonium sulfate, $100 \mathrm{mM}$ D-sorbitol and $125 \mu \mathrm{M}$ xylenol orange) was then added to the reaction mixture of peroxide and $\mathrm{Mb}$ and incubated at $22{ }^{\circ} \mathrm{C}$ for $30 \mathrm{~min}$. Finally, the colormetric reaction was read at $560 \mathrm{~nm}$ using a FLUOstar Omega plate reader (BMG LabTech, Mornington Victoria, Australia) and all quantitative data was normalized to the total protein (determined by standard bicinchoninic acid assay and using bovine serum albumin as the protein standard (Sigma-Aldrich, Sydney Australia). 


\subsubsection{Reduction of Myoglobin by Cytochrome 65 Reductase System}

Redox reactions with $\mathrm{hhMb}\left(50 \mu \mathrm{M}\right.$ final concentration) were performed at $22{ }^{\circ} \mathrm{C}$ in $250 \mathrm{mM}$ PBS ( $\mathrm{pH} 7.4$ ) and initiated by adding $\mathrm{HOCl}(0,5$ - and 10-fold mol excess). Reactions were terminated by adding $12.5 \mathrm{mM}$ L-Met on ice to scavenge excess $\mathrm{HOCl}$ and then gel filtration (disposable PD 10 Desalting Columns; GE Healthcare, Sydney, Australia) to remove residual L-Met and any low-molecular weight oxidation products. Subsequent to protein oxidation and gel purification, the one-electron reduction of native and $\mathrm{HOCl}$-oxidized ferric $\mathrm{hhMb}$ by added cytochrome $b 5$ was investigated as described in detail elsewhere [25,26]. Briefly, a sample $(10 \mu \mathrm{L})$ of the hhMb preparation (final $\mathrm{Mb}$ concentration $10 \mu \mathrm{M}$ ) was added to a reaction mixture containing $0.12 \mu \mathrm{M}$ human recombinant cytochrome b5, $0.05 \mu \mathrm{M}$ human NADPH-P450 reductase, glucose-6-phosphate (50 U), catalase (375 U), $20 \mathrm{mM}$ glucose, $0.2 \mathrm{mM}$ EDTA and $2 \mathrm{mM} \mathrm{NADP}^{+}$in $100 \mathrm{mM}$ phosphate buffer (pH 7.4). The reaction was carried out under air in a quartz cuvette and spectra (350 to $600 \mathrm{~nm}$ ) recorded every 1 min against a reference sample containing the reaction mixture without $\mathrm{Mb}$, using a Beckman Coulter DU800 UV/Vis Spectrophotometer maintained at $25 \pm 0.1^{\circ} \mathrm{C}$. All pseudo first-order rate constants were determined as averages of at least three separate determinations.

\subsubsection{Statistical Analyses}

All analyses were performed with Prism software (v3.0, GraphPad Inc., San Diego, CA, USA). Differences between groups were assessed with a one-way ANOVA and Tukey's multiple comparison test to minimize type- 1 and type- 2 statistical error. A value of $p<0.05$ was considered significant.

\section{Results}

To investigate the impact of reagent $\mathrm{HOCl}$ on myoglobin, native hhMb was treated with varying concentrations of reagent $\mathrm{HOCl}$ (Figure 1). A dose-dependent increase in post-translational modification to hhMb was observed as assessed by increased production of myoglobin oxidation products showing enhanced electrophoretic mobility (Figure 1; arrow denotes direction of in-gel migration with cathode and anode labeled) compared to vehicle control. Increased protein electrophoretic mobility was paralleled with marked changes to the visible region of the $\mathrm{Mb}$ electronic spectrum measured at $\mathrm{pH} 7.4$ for $\mathrm{HOCl}$-modified hhMb over a similar dose-range of this oxidant (Figure 2). Thus, $\mathrm{HOCl}$ stimulated a dose-dependent diminution in absorbance maxima observed at 542 and $580 \mathrm{~nm}$ (Figure 2). Taken together these findings indicate $\mathrm{HOCl}$ stimulated post-translational changes in native hhMb. This conclusion is supported by the altered electrophoretic mobility that manifested as HOCl-oxidation products of larger charge-to-size ratio migrating at a faster rate than the native protein towards the anode and $\mathrm{HOCl}$-oxidation impacting on the active site binding of the haem moiety, which in-turn alters the electronic absorbance characteristics of ferric hhMb.

Neutrophil-HOCl is known to damage the proteins by chlorination of tyrosine forming 3-chlorotyrosine (a specific marker of $\mathrm{HOCl}$ protein damage) [27]. To confirm whether this form of damage occurred in $\mathrm{hhMb}$ exposed to reagent $\mathrm{HOCl}$, levels of 3-chloro-tyrosine were measured and compared in native and $\mathrm{HOCl}$-treated $\mathrm{hhMb}$. Analysis of protein chlorination by quantitative mass spectrometry revealed an increase in the 3-chlorotyrosine/tyrosine ratio in $\mathrm{Mb}$ exposed to $\mathrm{HOCl}$ at ratios $\geq 10 \mathrm{~mol} / \mathrm{mol}$ (Figure 3 ). The response to treatment with reagent $\mathrm{HOCl}$ was again dose-dependent when compared to vehicle control albeit the proportion of tyrosine modified by chlorination remained extremely low with only $\sim 0.2 \pm 0.1 \%$ of total tyrosine detected as the 3-Cl-Tyr modified product at the highest dose of reagent $\mathrm{HOCl}$ tested in our hands. This later observation indicated that the 3-Cl-Tyr modified product was formed in low overall yield and was unlikely to be causally linked to other physical-chemical changes in hhMb exposed to reagent $\mathrm{HOCl}$. 
A

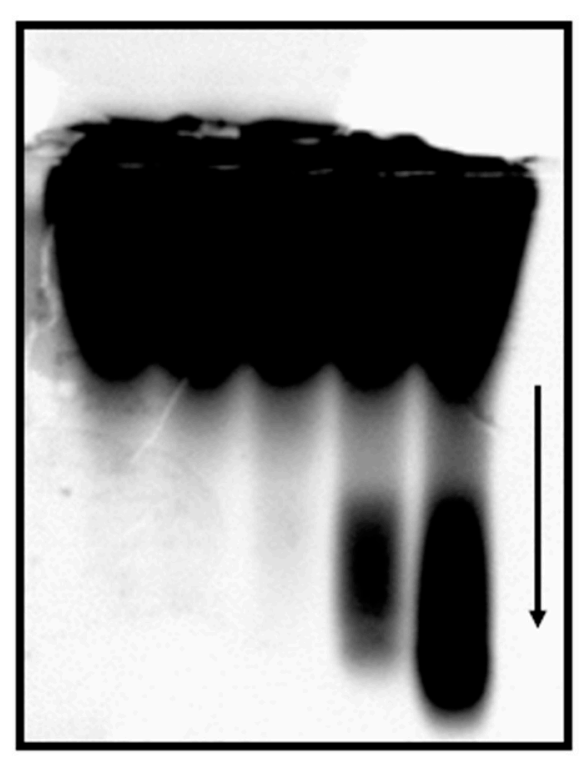

Cathode

\section{Anode}

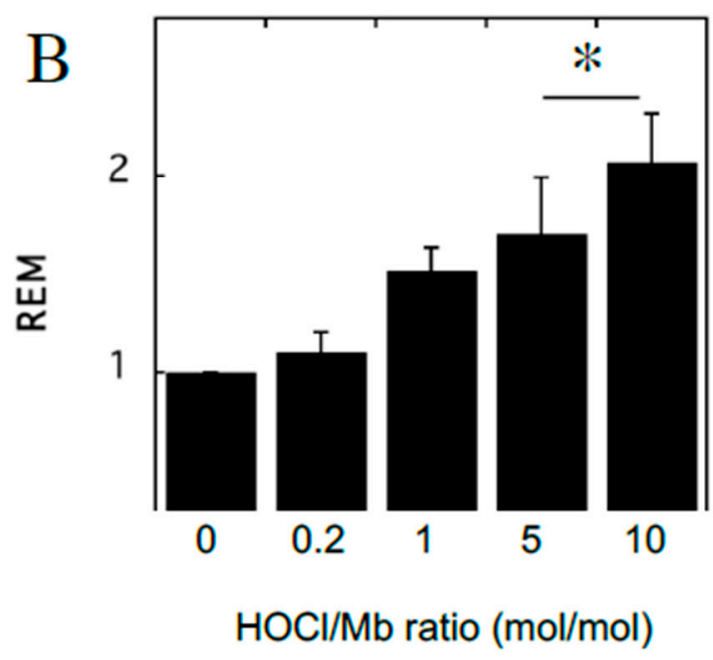

Figure 1. Modification of horse heart myoglobin (hhMb) with reagent $\mathrm{HOCl}$ increases electrophoretic mobility of the protein. Solutions of hhMb (final concentration $25 \mu \mathrm{M}$ ) were exposed to increasing dose of reagent $\mathrm{HOCl}$ (final ratio $\mathrm{HOCl} / \mathrm{hhMb} \mathrm{mol} / \mathrm{mol}$ indicated). An aliquot was diluted $10 \times$ in phosphate buffer (50 mM, pH 7.5) and (A) loaded onto an agarose gel and protein separated by an applied electric field and stained using Coomassie Blue as described in the Methods section (arrow indicates direction of migration in the electric field). (B) Relative electrophoretic mobility (REM; measured as the distance travelled in the gel) was then calculated for each reaction condition and expressed as mean $\pm \mathrm{SD} ; n=3$. * Different to the vehicle control in the absence of added reagent $\mathrm{HOCl} ; p<0.05$. 


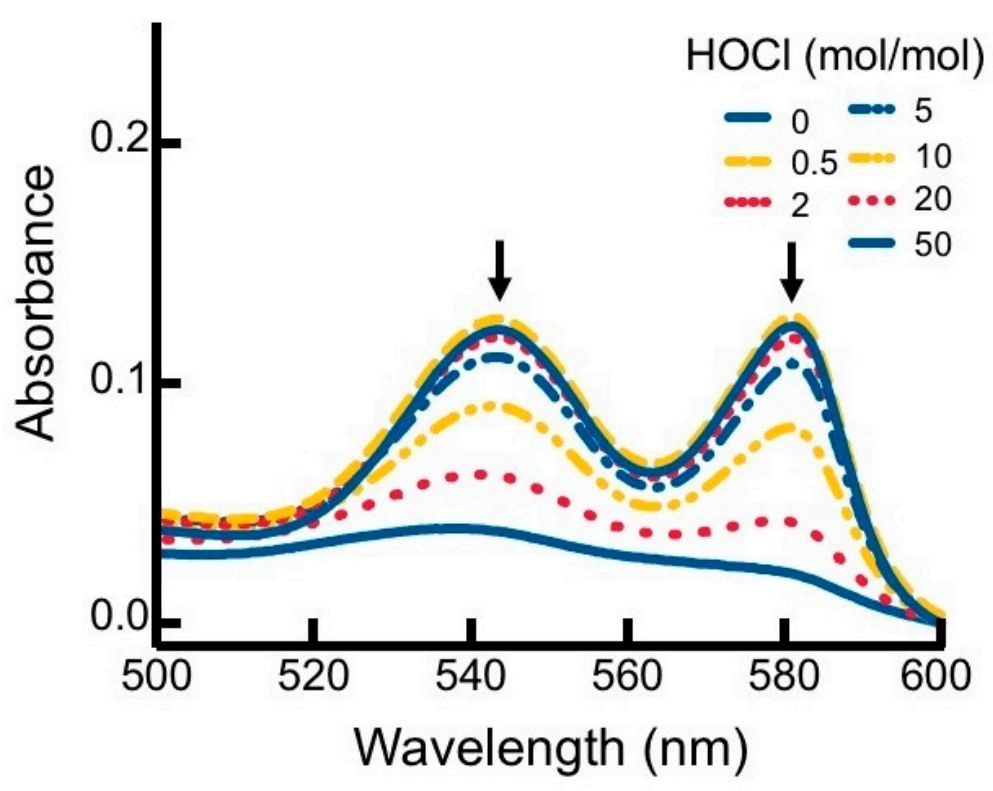

Figure 2. Alterations to the visible region of the $\mathrm{hhMb}$ absorbance spectrum in the presence of regent $\mathrm{HOCl}$. Solutions of hhMb (final concentration $10 \mu \mathrm{M}$ ) were exposed to increasing dose of reagent $\mathrm{HOCl}$ (final ratio $\mathrm{HOCl} / \mathrm{hhMb} \mathrm{mol} / \mathrm{mol}$ indicated). Aliquots of the reaction mixture were diluted $(10 \mathrm{x})$ in phosphate buffer (50 mM, pH 7.5) and transferred to a quartz cuvette and absorbance measured in the region 500-600 nm. Data are representative of $n=3$ independent experiments using freshly prepared $\mathrm{HOCl}$-modified hhMb. Arrows indicate a diminution in absorbance maxima at 542 and $580 \mathrm{~nm}$.

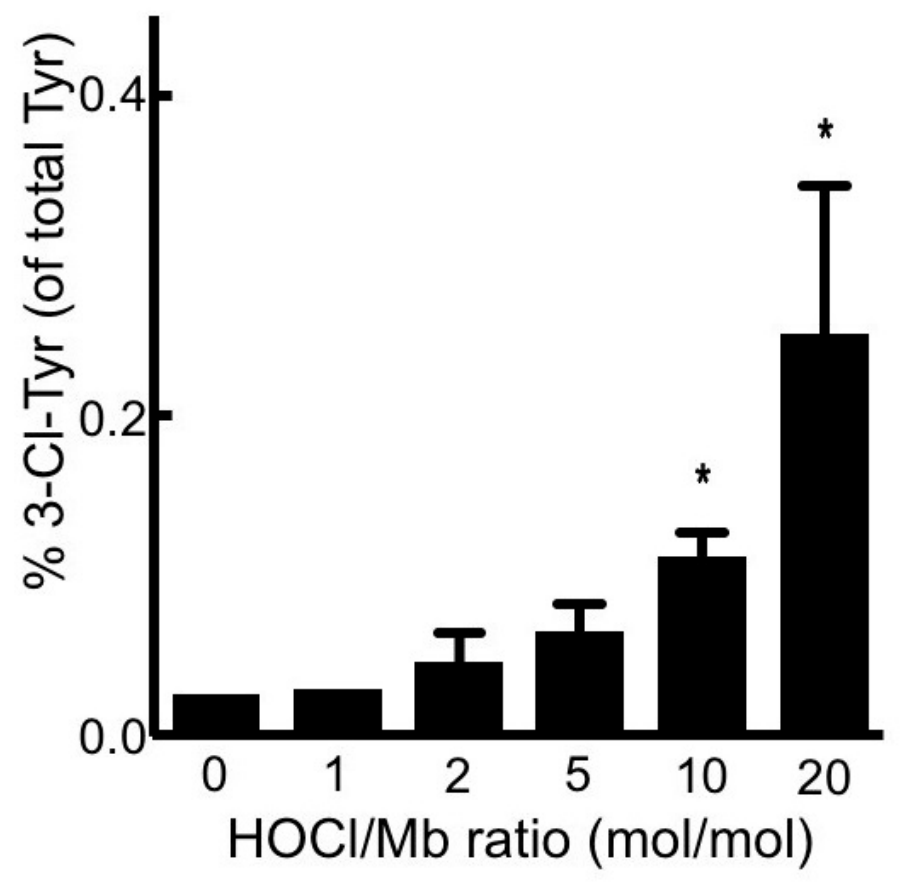

Figure 3. Treatment of hhMb with reagent $\mathrm{HOCl}$ increases the level of 3-chlorotyrosine tyrosine relative to native tyrosine in the protein. Solutions of $\mathrm{hhMb}$ (final concentration $50 \mu \mathrm{M}$ ) were exposed to increasing dose of reagent $\mathrm{HOCl}$ (final ratio $\mathrm{HOCl} / \mathrm{hhMb} \mathrm{mol} / \mathrm{mol}$ indicated). Aliquots of reaction mixture were precipitated in ice-cold acetone (total $100 \mu \mathrm{g}$ protein) and then processed and purified for quantitative mass spectrometry as described in the Methods section. Data represent mean \pm SD; $n=3$ independent preparations of $\mathrm{hhMb}$. ${ }^{*}$ Different to the vehicle control in the absence of added reagent $\mathrm{HOCl} ; p<0.05$. 
After establishing that low-level chlorination could occur in this system, we sought to confirm whether other post-translational amino acid modifications occurred after exposing hhMb to reagent $\mathrm{HOCl}$ (final ratios hhMb: $\mathrm{HOCl}$ ranging 0,5 or $10 \mathrm{~mol} / \mathrm{mol}$ ). Mixtures of hhMb and $\mathrm{HOCl}$ were initially separated by liquid chromatography (Figure $4 \mathrm{~A}$ ). In the absence of $\mathrm{HOCl}$, native $\mathrm{Mb}$ eluted primarily as a single major peak eluting at $18.5 \mathrm{~min}$ with minor shoulder peaks at $\sim 18 \mathrm{~min}$. Treating hhMb with $5 \mathrm{~mol} \mathrm{HOCl} / \mathrm{mol}$ protein markedly diminished the large peak eluting at $18.5 \mathrm{~min}$ (corresponding to native $\mathrm{hhMb}$ ) and new products were detected eluting at 16.6, 17.5 and $\sim 18 \mathrm{~min}$. The intensity of these product peaks increased further upon exposing hhMb to $10 \mathrm{~mol} \mathrm{HOCl} / \mathrm{mol}$ protein where almost all native $\mathrm{hhMb}$ was depleted under these latter harsh oxidizing conditions (i.e., a weak peak response eluting at $18.5 \mathrm{~min}$ was detected but this response was lower than other eluting forms of oxidized hhMb).
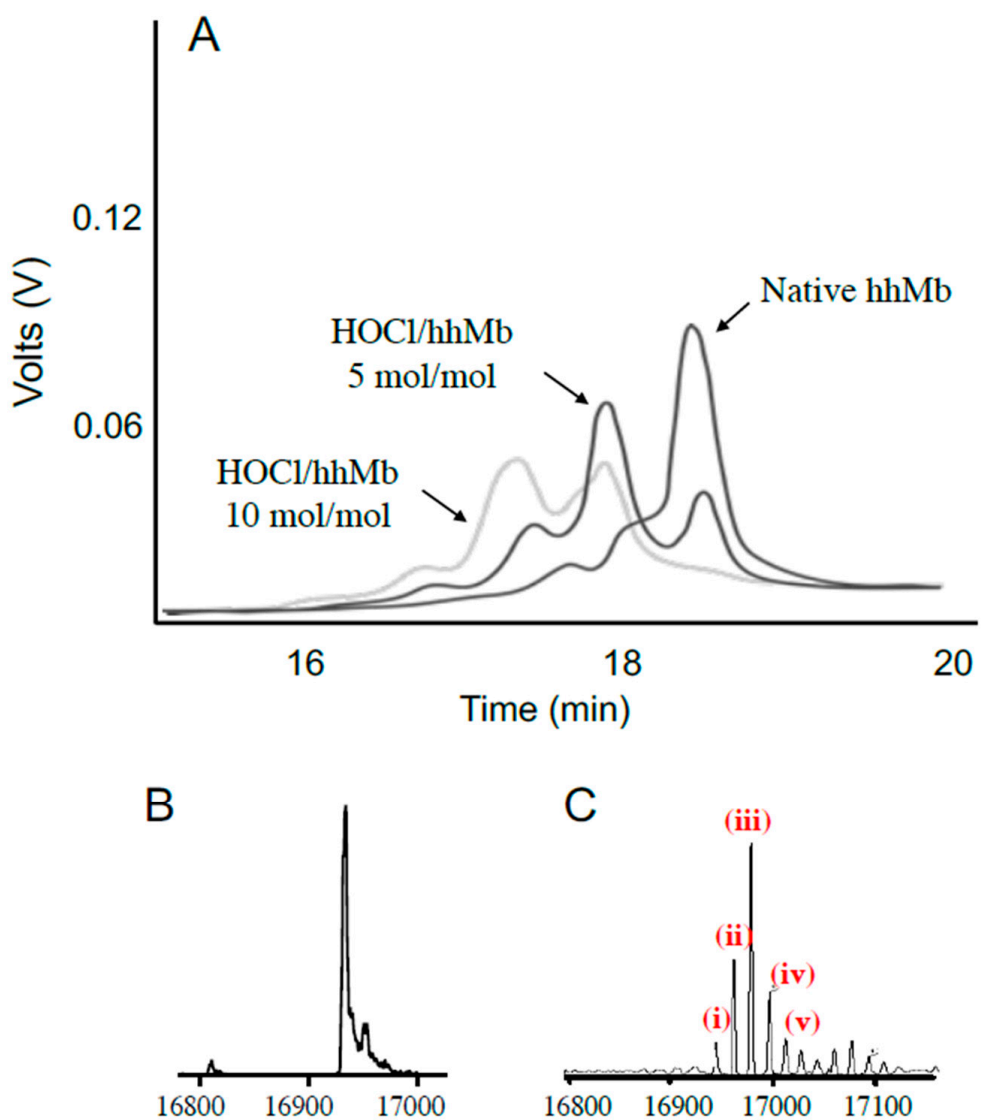

$\operatorname{Mass}(\mathbf{m} / \mathbf{z})$

Figure 4. Oxidation of $\mathrm{hhMb}$ with reagent $\mathrm{HOCl}$ generates a complex mixture of products. Solutions of $\mathrm{hhMb}$ were exposed to vehicle (control) or 5 and $10 \mathrm{~mol} / \mathrm{mol}$ excess reagent $\mathrm{HOCl}$. Aliquots of control or $\mathrm{HOCl}$-modified hhMb were then applied to a chromatographic system and the protein elution profile was monitored as described in the Methods section. Panel (A) shows several representative expanded elution profiles for hhMb eluting between 16-20 min. The deconvoluted mass spectrum of $\mathrm{hhMb}$ treated with vehicle control (seen primarily as a single peak of mass $16951.2 \mathrm{~m} / \mathrm{z}$. (Panel (B)) or $10 \mathrm{~mol} \mathrm{HOCl} / \mathrm{mol} \mathrm{hhMb}$ protein (shown in Panel (C)) detected as multiple peaks identified by different masses ranging from $\sim 16,966$ to $\sim 16,999 \mathrm{~m} / \mathrm{z}$. In panel $\mathrm{C}$, the labeled peaks correspond to (i) residual native protein $(16,951.2 \mathrm{~m} / \mathrm{z}$ ); mass peak at (ii) 16,966.9 (assigned as $\mathrm{hhMb}+15.7 \mathrm{~m} / \mathrm{z}$. corresponding to $\sim 1$ oxygen atom), (iii) 16,983.2 (assigned as hhMb $+31.7 \mathrm{~m} / z$ corresponding to $\sim 2$ oxygen atoms), (iv) $16,999.0$ (assigned as $\mathrm{hhMb}+47.8 \mathrm{~m} / \mathrm{z}$ corresponding to $\sim 3$ oxygen atoms) and (v) 17,015.3 (assigned as $+63.8 \mathrm{~m} / z$ corresponding to $\sim 4$ oxygen atoms). These latter peaks corresponded to the sequential addition of 1-4 oxygen atoms to the protein backbone. 
Subsequently, samples of native or $\mathrm{HOCl}$-modified $\mathrm{Mb}(10 \mathrm{~mol} \mathrm{HOCl} / \mathrm{mol}$ protein) were assessed with mass spectrometry (Figure $4 \mathrm{~B}, \mathrm{C}$ ). In the absence of $\mathrm{HOCl}$ the vehicle treated hhMb showed a single mass peak with mass $16,951.2 \mathrm{~m} / \mathrm{z}$ in the deconvoluted spectrum, which closely matches the previously reported value for native $\mathrm{hhMb}(16,951.5 \mathrm{~m} / \mathrm{z})$ [28]. Clearly, treatment of hhMb with reagent $\mathrm{HOCl}$ yielded a complex mixture of products with the corresponding deconvoluted mass spectrum showing multiple mass peaks, with the major peak responses differing by multiples of $\sim 16$ (compare the multiple peaks marked (i-v), Figure $4 \mathrm{C}$ with native hhMb sample exposed to PBS as a vehicle control, Figure $4 \mathrm{~B}$ as listed in the legend to the figure). These mass changes were consistent with successive covalent addition of molecular oxygen to the protein that was previously ascribed to methionine (Met) residue sulfoxidation at Met55 and Met131 and tryptophan (Trp) residue oxidation at Trp 7 and Trp 14 in the hhMb sequence as defined previously in hhMb using LC/MS tandem MS/MS [21]; the extent of amino acid oxidation followed the reactivity order Met55 > Met131 > Trp7 > Trp14 [21]. While addition of molecular oxygen to methionine simply yields the corresponding sulfoxide, oxidation of Trp is more complex with 3-hydroytryptophan forming an equilibrium with the corresponding 3-keto analogue that can subsequently yield kynurenine in the presence of excess oxidant through the intermediate N-formyl kynurenine [29].

Taken together the post-translational modifications identified by mass analyses have collectively revealed that $\mathrm{HOCl}$-mediated $\mathrm{hhMb}$ oxidation yielded a mixture of chlorinated protein (relatively minor product) and a modified protein that contains sequential addition of molecular oxygen (relatively major products) with the extent of oxidation being dependent on the ratio of oxidizing $\mathrm{HOCl}$ to target protein employed. Interestingly, we have shown previously that oxidized myoglobin is present in the damaged myocardium after experimental heart attack in rats, however, no evidence of 3-chlorotyrosine was detected in gel purified rat heart $\mathrm{Mb}$ [30], which is completely consistent with the majority of $\mathrm{HOCl}$ oxidation of $\mathrm{Mb}$ yielding serial addition of molecular oxygen at redox active amino acids rather than producing detectable tyrosine chlorination.

Under physiological conditions myoglobin reacts with $\mathrm{H}_{2} \mathrm{O}_{2}$ to neutralize the oxidants in a peroxidase-like reaction that yields water and a protein radical (designated as a myoglobin ferryl porphyrin cation radical $\left(\mathrm{MbFe}(\mathrm{IV})=\mathrm{O}^{+\bullet}\right)$ ) that can be translocated through an intramolecular electron-transfer reaction with various reactive amino acids on the protein backbone [31,32]. As anticipated, the reaction of native hhMb with $\mathrm{H}_{2} \mathrm{O}_{2}$ at $22^{\circ} \mathrm{C}$ yielded a DMPO spin-trapped adduct, in the absence of reagent $\mathrm{HOCl}$, with a characteristic hyperfine coupling pattern that has been previously assigned to a tyrosyl radical generated at tyrosine residue 103, the Tyr residue residing closest to the $\mathrm{Mb}$-haem prosthetic group [31]. Overall, pre-treatment of hhMb with reagent $\mathrm{HOCl}$ dose-dependently decreased the level of spin-trapped tyrosyl radical detected by EPR spectroscopy (Figure 5A-C). By contrast, in the absence of hhMb no significant signal was detected (Figure 5D). Taken together this outcome can be interpreted in two possible ways (i) HOCl-mediated modification of the protein decreases $\mathrm{Mb}$ pseudo-peroxidase activity or (ii) $\mathrm{HOCl}$-mediated modification of the protein has no impact on the generation of $\mathrm{MbFe}(\mathrm{IV})=\mathrm{O}^{+} \bullet$ but instead inhibits the intramolecular electron translocation of the $\mathrm{MbFe}(\mathrm{IV})=\mathrm{O}^{+\bullet}$ to the protein backbone, a process which is documented to involve either intramolecular reduction of the $\mathrm{MbFe}(\mathrm{IV})=\mathrm{O}^{+\bullet}$ by amino acids such as tryptophan and tyrosine within hhMb [22,33]; or the intermolecular reaction with tyrosine residues on other proteins [34]. 


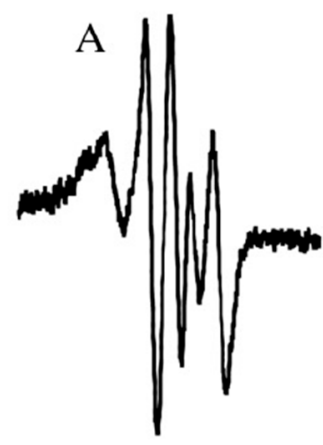

$0: 1$

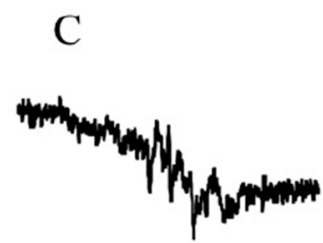

$10: 1$
B

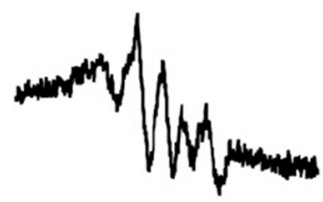

$5: 1$

$\mathrm{D}$

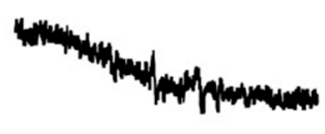

$\mathrm{DMPO}+\mathrm{HOCl}$

\section{HOCl/Mb ratio (mol:mol)}

Figure 5. Treatment of hhMb with regent $\mathrm{HOCl}$ inhibits the formation of protein-centered radicals as detected by spin trapping. Solutions of hhMb (final concentration $500 \mu \mathrm{M}$ ) were exposed to an increasing dose of reagent $\mathrm{HOCl}$ (final oxidant:protein mol ratio indicated in the representative spectra shown in panels (A) Control; (B) hhMb pretreated with $\mathrm{HOCl} 5 \mathrm{~mol} / \mathrm{mol}$ protein; (C) hhMb pretreated with $\mathrm{HOCl} 10 \mathrm{~mol} / \mathrm{mol}$ protein and (D) absence of hhMb). All hhMb solutions contained $100 \mu \mathrm{M}$ the chelator diethylenetriaminepentaacetic acid (DTPA). Aliquots of reaction mixture were then treated with hydrogen peroxide (final ratio $\mathrm{H}_{2} \mathrm{O}_{2}: \mathrm{hhMb} \sim 5 \mathrm{~mol} / \mathrm{mol}$ ) or phosphate buffer (as a vehicle control) in the presence of $5 \mathrm{mM}$ 5,5-dimethyl-1-pyrroline N-oxide (DMPO) as described in the Methods section. The reaction mixture was then rapidly transferred to a flat cell and radical generation assessed using EPR spectroscopy with the following parameters: Microwave power $20 \mathrm{~mW}$, modulation amplitude $0.1 \mathrm{mT}$, modulation frequency of $100 \mathrm{kHz}$ and a sweep time of $84 \mathrm{~s}$. EPR spectra were obtained as a cumulative average of five consecutive scans. No signal was obtained in the absence of DMPO or $\mathrm{H}_{2} \mathrm{O}_{2}$ (data not shown). Data are representative of $n=3$ independent experiments using freshly prepared protein radicals.

To explore whether $\mathrm{Mb}$ pseudo-peroxidase activity was altered, we assessed the ability for hhMb to oxidize ABTS and compared rates of ABTS oxidation in the presence of native and HOCl-modified $\mathrm{hhMb}$. Overall, the pseudo-first order rate constant for ABTS oxidation by mixtures of hhMb/ $\mathrm{H}_{2} \mathrm{O}_{2}$ decreased in a HOCl-dose dependent manner (Figure 6) indicating that post-translational modification of hhMb affected its ability to oxidize an exogenous substrate (ABTS). This outcome, identified here for the first time, suggests that the reaction between $\mathrm{Fe}(\mathrm{III}) \mathrm{Mb}$ and peroxide to form $\mathrm{MbFe}(\mathrm{IV})=\mathrm{O}^{+} \bullet$ (that is subsequently reduced by the exogenous substrate ABTS) is less efficient when hhMb is first oxidized with $\mathrm{HOCl}$. Therefore, in reactions between $\mathrm{H}_{2} \mathrm{O}_{2}$ and $\mathrm{HOCl}$-modified hhMb the capacity to generate the porphyrin radical cation is inhibited and therefore, it is likely that fewer protein radicals are formed by intramolecular electron transfer between the porphyrin radical cation to the protein backbone simply due to a decreased availability of the $\mathrm{MbFe}(\mathrm{IV})=\mathrm{O}^{+\bullet}$ as a result of the diminished peroxidase activity for $\mathrm{HOCl}$-modified hhMb. 

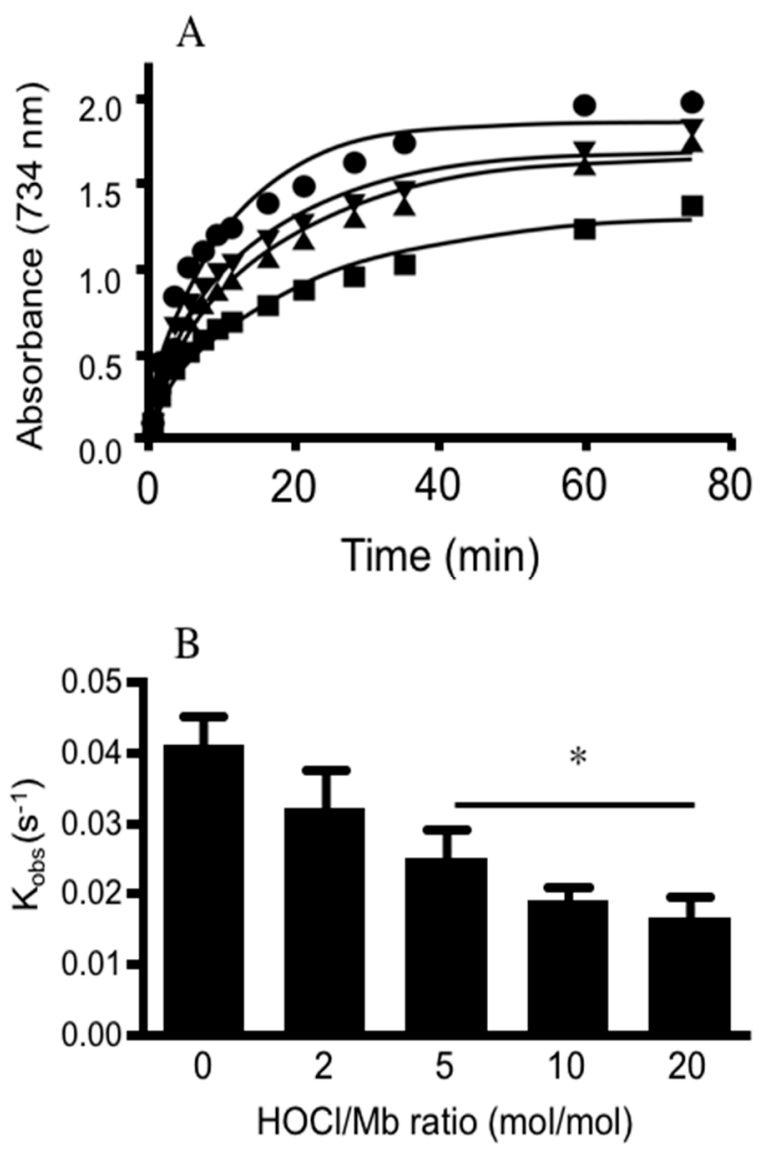

Figure 6. Treatment of hhMb with regent $\mathrm{HOCl}$ inhibits ABTS oxidation initiated by $\mathrm{H}_{2} \mathrm{O}_{2}$. Solutions of hhMb containing the chelator DTPA $(100 \mu \mathrm{M})$ were exposed to vehicle (control) or increasing dose of reagent $\mathrm{HOCl}$ (final ratio $\mathrm{hhMb} / \mathrm{HOCl} \mathrm{mol} / \mathrm{mol}$ as indicated). Aliquots of control or HOCl-modified $\mathrm{hhMb}$ were then transferred to a quartz cuvette containing excess ABTS and hydrogen peroxide (final ratio $\mathrm{H}_{2} \mathrm{O}_{2}: \mathrm{hhMb} \sim 5 \mathrm{~mol} / \mathrm{mol}$ ) or excess ABTS with phosphate buffer (50 mM, pH 7.4, control) as described in the Methods section. For all studies the final hhMb concentration in the cuvette was maintained at $25 \mu \mathrm{M}$. Next, (A) the rate of ABTS radical cation formation was monitored over time at $734 \mathrm{~nm}$. Reaction conditions were as follows: (closed circle) vehicle control; (inverted triangle) hhMb treated with $2 \mathrm{~mol} / \mathrm{mol} \mathrm{HOCl}$; (filled triangle) hhMb treated with $5 \mathrm{~mol} / \mathrm{mol} \mathrm{HOCl}$ and (filled square) $\mathrm{hhMb}$ treated with $10 \mathrm{~mol} / \mathrm{mol} \mathrm{HOCl}$. Note for clarity samples treated with $20 \mathrm{~mol} / \mathrm{mol} \mathrm{HOCl}$ were not shown on the graph. (B) First order rate constants were then determined from the initial rapid increase in $\mathrm{ABTS}$ oxidation and plotted against $\mathrm{HOCl} / \mathrm{hhMb}$ ratio in the reaction mixture. Data represent mean $\pm \mathrm{SD} ; n=3$ independent kinetic studies using different preparations of hhMb. ${ }^{*}$ Different to the vehicle control in the absence of added reagent $\mathrm{HOCl} ; p<0.05$.

Next, we evaluated the impact of reagent $\mathrm{HOCl}$ on $\mathrm{Mb}$ catalase-like activity. This catalytic activity also involves conversion of $\mathrm{MbFe}(\mathrm{III})$ to $\mathrm{MbFe}(\mathrm{IV})=\mathrm{O}^{+} \bullet$. However, in the absence of a suitable substrate $\mathrm{MbFe}(\mathrm{IV})=\mathrm{O}^{+\bullet}$ can act as a two-electron oxidant toward excess peroxide, generating water, oxygen and subsequently recycling $\mathrm{MbFe}(\mathrm{III})$ in this reaction. Initially, we tested the time-dependent consumption of $\mathrm{H}_{2} \mathrm{O}_{2}$ in the presence of $\mathrm{hhMb}$ to ascertain an appropriate time to assess residual peroxide levels after the reaction had reached near completion (i.e., achieved a steady state). Addition of $\mathrm{hhMb}$ to a fixed concentration of $\mathrm{H}_{2} \mathrm{O}_{2}(200 \mu \mathrm{M})$ resulted in a rapid depletion of the peroxide in the first 2-5 min of the reaction; the reaction rate decreased over the ensuing $20 \mathrm{~min}$ and achieved a steady-state at $\sim 15 \mathrm{~min}$ (Figure 7A, inset); this time was judged as suitable to determine whether $\mathrm{HOCl}$-oxidation of hhMb affected the protein's catalase-like activity. In contrast with the measurement of peroxidase activity that was sensitive to reagent $\mathrm{HOCl}$, steady state determinations of hhMb catalase-like activity remained 
unaffected by $\mathrm{HOCl}$ as judged by the similar extent of $\mathrm{H}_{2} \mathrm{O}_{2}$ degradation (consistently $~ 80-85 \%$ of the initial $\mathrm{H}_{2} \mathrm{O}_{2}$ concentration was consumed) in the presence of native or $\mathrm{HOCl}$-oxidized hhMb under the same experimental conditions (Figure 7A). That is, while the depletion of $\mathrm{H}_{2} \mathrm{O}_{2}$ was significantly different for all the $\mathrm{hhMb}$ proteins compared with vehicle alone (addition of vehicle containing no protein) there was no difference in the extent of $\mathrm{H}_{2} \mathrm{O}_{2}$ depletion amongst the native or $\mathrm{HOCl}$-oxidized proteins tested. This ability for $\mathrm{hhMb}$ to act as a catalase antioxidant mimetic was relatively selective for $\mathrm{H}_{2} \mathrm{O}_{2}$ since degradation of an organic peroxide (cumene hydroperoxide; $\mathrm{C}-\mathrm{OOH}$ ) was markedly less efficient than the degradation of $\mathrm{H}_{2} \mathrm{O}_{2}$ under the identical reaction conditions (comparatively only $\sim 12-18 \%$ of the initial C-OOH concentration is consumed; c.f., Figure 7A,B). Interestingly, this diminished capacity to degrade the organic peroxide- $\mathrm{OOH}$ also remained independent of the extent of $\mathrm{HOCl}$ oxidation as the extent of $\mathrm{C}-\mathrm{OOH}$ degradation remained largely the same for both native and all $\mathrm{HOCl}$-modified hhMb tested. That is, similar to the case with $\mathrm{H}_{2} \mathrm{O}_{2}$, the depletion of $\mathrm{C}-\mathrm{OOH}$ was significantly different for all the hhMb proteins compared with vehicle alone (compared with vehicle-treated peroxide containing no protein) yet there was no difference in the extent of cumene hydroperoxide depletion when comparing the native and HOCl-oxidized proteins tested.
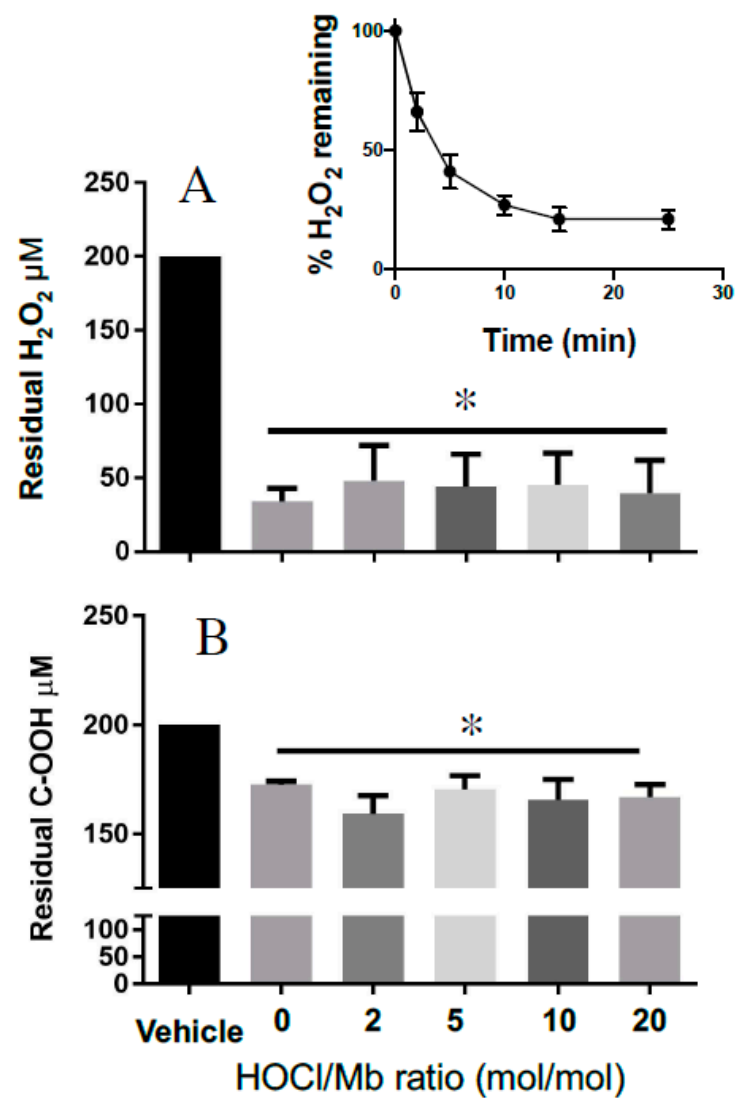

Figure 7. Catalase-like activity of hhMb is unaltered by oxidation with reagent HOCl. Samples of native or reagent $\mathrm{HOCl}$-oxidized $\mathrm{hhMb}(\mathrm{HOCl}: \mathrm{Mb}$ ratio as indicated in the figure; final concentration of hhMb $25 \mu \mathrm{M}$ ) were added to a reaction mixture containing $\sim 0.2 \mathrm{mM}$ peroxide for $15 \mathrm{~min}$, then the mixture was treated with xylenol orange and residual peroxide calculated using a modified FOX-1 assay as described in detail in the Methods section. After mixing in a quartz cuvette the reaction was placed in a spectrometer and peak absorbance was monitored at $560 \mathrm{~nm}$ at $22{ }^{\circ} \mathrm{C}$. Panels show $\mathrm{Mb}$-mediated degradation of $(\mathbf{A}) \mathrm{H}_{2} \mathrm{O}_{2}$ and $(\mathbf{B})$ cumene hydroperoxide $(\mathrm{C}-\mathrm{OOH})$. Data represent the mean $\pm \mathrm{SD} ; n=3$ independent experiments using different batches of native hhMb and freshly prepared HOCl-modified $\mathrm{hhMb}$. * Different to the vehicle control in the absence of added reagent $\mathrm{HOCl} ; p<0.05$. 
Finally, to test whether $\mathrm{HOCl}$-induced modifications in hhMb impacted the rate or extent of one-electron reduction by a reduced cytochrome $b 5$ reductase system we monitored changes in the rate constant of intermolecular electron transfer to the haem-iron bound within hhMb through monitoring the Soret region with UV-Vis spectroscopy. Overall, similar to the case for recombinant human $\mathrm{Mb}$ [35], pre-treatment of $\mathrm{hhMb}$ with reagent $\mathrm{HOCl}$ decreased the cytochrome b5-mediated reduction of hhMbFe(III) haem in a dose-dependent manner and resulted in a significantly decreased observed rate constant for $\mathrm{hhMb}$ one-electron reduction compared to native (unmodified) hhMb measured under identical experimental conditions (Figure 8). As maintenance of the $\mathrm{MbFe}(\mathrm{II})$ form is essential for oxygen binding and transport in muscle tissues, any change in the rate of chemical reduction of the haem-iron centre in hhMb may impact on the capacity of the protein to perform this function and subsequently impact on tissue oxygenation levels and oxygen delivery to mitochondria.
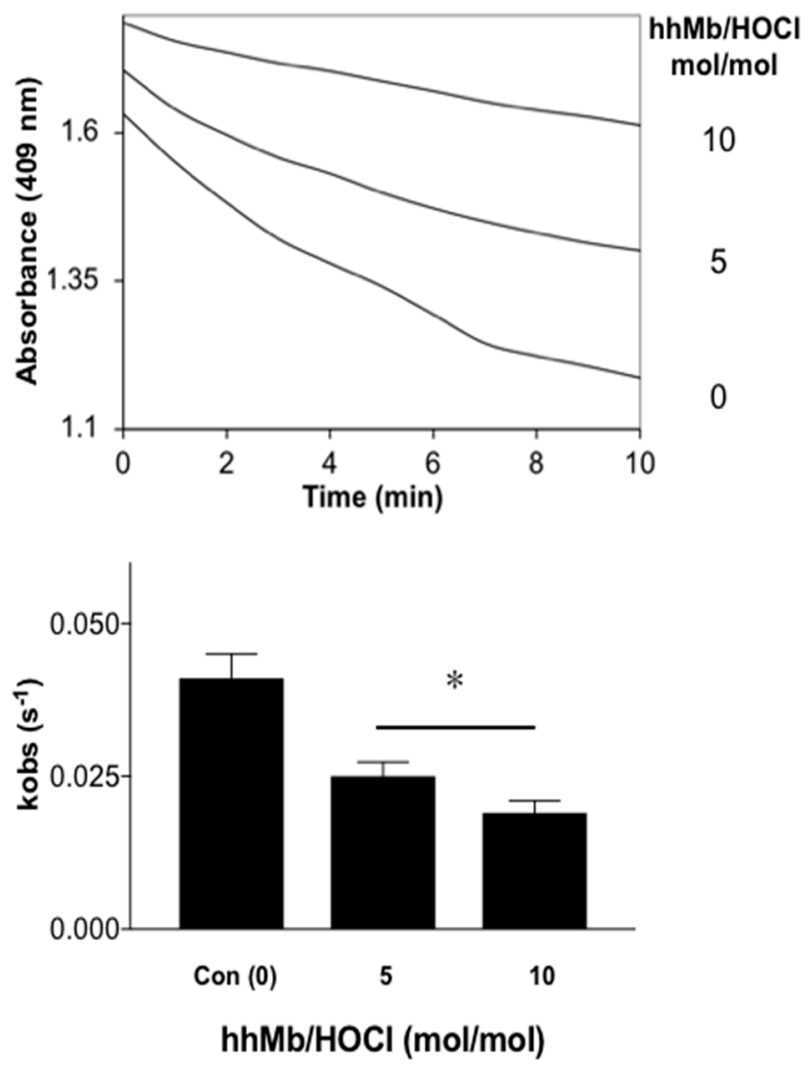

Figure 8. Rates of reduction of Fe(III)-to-Fe(II) in native and HOCl-modified hhMb by a cytochrome $b 5$ reductase system. Samples of native or reagent $\mathrm{HOCl}$-oxidized hhMb (final $\mathrm{HOCl}: \mathrm{Mb}$ ratio 5 or $10 \mathrm{~mol}$ oxidant:mol protein; final concentration of $\mathrm{hhMb} 10 \mu \mathrm{M}$ ) were added to a reaction mixture containing $\sim 0.2 \mu \mathrm{M}$ recombinant cytochrome $b 5$ protein, $0.1 \mu \mathrm{M}$ NADPH-P450 reductase and an enzymic reductase system as described in detail in the Methods section. After mixing in a quartz cuvette the reaction was placed in a spectrometer and peak absorbance was monitored at $409 \mathrm{~nm}$ and $25^{\circ} \mathrm{C}$. (A) Time-dependent change in $\mathrm{A}_{409} \mathrm{~nm}$ for cytochrome b5-mediated one-electron reduction of hhMb. (B) First-order rate constant estimated for the kinetic reduction of $\mathrm{hhMb}$ over the initial linear phase (0-10 min). Data represent the mean $\pm \mathrm{SD} ; n=3$ independent experiments using different batches of $\mathrm{Mb}$ and fresh solutions of cytochrome $b 5$ and reductase system. * Different to the vehicle control in the absence of added reagent $\mathrm{HOCl} ; p<0.05$.

\section{Discussion}

Exposure to $\mathrm{HOCl}$ causes changes in myoglobin structure as judged by a series of biochemical outcomes including changes to electrophoretic mobility and absorbance in the visible region of the $\mathrm{hhMb}$ electronic spectrum together with the confirmation that $\mathrm{HOCl}$-oxidized hhMb contains both 
oxygenated (major) and chlorinated (minor) products; albeit that chlorination is a minor pathway compared with a HOCl-dose dependent serial addition of molecular oxygen to $\mathrm{Mb}$ residues Met and Trp. These post-translational modifications resulted in an altered capacity to react with $\mathrm{H}_{2} \mathrm{O}_{2}$ (that is, a diminished pseudo-peroxidase activity) and inhibited the rate of intermolecular one-electron reduction between hhMbFe(III) and a cytochrome $b 5$ reductase system [15], although oxidation by reagent $\mathrm{HOCl}$ had no material bearing on $\mathrm{Mb}$ catalase-like antioxidant activity. Of biological consequence, it is established that $\mathrm{Mb}$ exists in high abundance in the myocardium [7] and is an essential oxygen binding protein. Therefore, alterations to its structure and function through oxidative modification under acute inflammatory conditions has the potential to negatively impact on $\mathrm{Mb}$-mediated oxygen storage and transport rendering cardiac muscle vulnerable to hypoxia-reoxygenation injury. If this were to occur in the inflamed myocardium, where recruitment of neutrophils to the periphery of the infarct occurs post AMI, then cardiomyocytes surrounding the primary infarct region may undergo secondary oxidant stress from $\mathrm{HOCl}$ produced by the infiltrating neutrophils leading to an expansion of the necrotic region that further diminishes ventricular function.

Data generated here demonstrates that $\mathrm{HOCl}-$ mediated oxidation of hhMb impacted $\mathrm{Mb}$ pseudo-peroxidase activity yielding a HOCl-dose-dependent inhibition of ABTS oxidation coupled with a diminished capacity to produce protein-centered radicals (specifically tyrosyl radicals localized to Tyr103) in hhMb [36]. Formation of relatively long-lived protein tyrosyl radicals are a hallmark of the reaction between mammalian $\mathrm{Mbs}$ and $\mathrm{H}_{2} \mathrm{O}_{2}[22,31,37]$ and subsequent covalent crosslinking of the haem prosthetic group to the protein reportedly involves Tyr103 [38]. However, exposure of $\mathrm{hhMb}$ to reagent $\mathrm{HOCl}$ inhibits the translocation of oxidizing equivalence to the protein in the presence of $\mathrm{H}_{2} \mathrm{O}_{2}$ suggesting that intramolecular electron transfer from redox active amino acids within the $\mathrm{Mb}$ protein to the $\mathrm{MbFe}(\mathrm{IV})=\mathrm{O}^{+\bullet}$ radical (referred to as $\mathrm{Mb}$-compound $\mathrm{I}$ ) has been impeded, which should decrease intramolecular secondary reduction reactions involving redox active amino acids and paradoxically enhance peroxidase activity through cycling Mb-compound I to the ferryl-iron(IV)-oxo haem species $(\mathrm{MbFe}(\mathrm{IV})=\mathrm{O}$; referred to as $\mathrm{Mb}$-compound $\mathrm{II})$, which then cycles further to the resting state $\mathrm{MbFe}(\mathrm{III})$ ready for peroxidase activation by excess $\mathrm{H}_{2} \mathrm{O}_{2}$.

Through identifying specific amino acids that are modified by $\mathrm{HOCl}$ in mammalian $\mathrm{Mbs}$ we have developed an understanding of the order of damage to amino acids in the protein sequence [21] with the order of susceptibility to HOCl-mediated oxidation according to the sequence Met55 > Met131 > Trp7 > Trp14. Interestingly, Trp radicals are detected using low temperature electron paramagnetic spectroscopy techniques [32] and are formed prior to tyrosyl radicals via intramolecular electron transfer reactions involving $\mathrm{Mb}$ compound I and Trp7/14; subsequently a second intramolecular electron transfer event yields tyrosyl radicals as the radical sink in mammalian Mbs [31,36]. Therefore, it is feasible that HOCl-mediated Trp oxidation inhibits the downstream formation of Trp protein radicals and this leads to the diminished detection of DMPO-trapped Tyr radicals (Figure 5).

Both $\mathrm{Mb}$ compound I and compound II can oxidize substrates in the peroxidase cycle, which is the case for professional peroxidase enzymes such as horse radish peroxidase that are able to cycle at high turnover in the absence of self-oxidation $[39,40]$. The precise mechanism that explains this decreased peroxidase activity through inhibiting electron transfer processes between the haem-iron center and amino acid residues within the protein were not explored completely in this study, albeit that diminished production of $\mathrm{Mb}$ compound I was implied by our data. However, it is clear that tyrosine chlorination is unlikely to be a major pathway that impedes peroxidase enzyme turnover since the absolute proportion of 3-Cl-Tyr/native tyrosine was extremely low in HOCl-oxidized hhMb (in the order 2.4 chlorination products per 1000 Tyr residues), indicating that a majority of tyrosine in the protein was not modified by reagent $\mathrm{HOCl}$ and therefore, this amino acid remained available to reduce $\mathrm{MbFe}(\mathrm{IV})=\mathrm{O}^{+\bullet}$ that formed in reaction with peroxide. However, spin trapping of the hhMb-tyrosyl radical with DMPO indicated that formation of the tyrosine phenoxyl radicals was diminished by $\mathrm{HOCl}$ in a dose-dependent fashion hence we concluded that $\mathrm{HOCl}$-modification of hhMb impacts the formation of $\mathrm{Mb}$ compound I. In contrast to Tyr, $\mathrm{HOCl}$-oxidized damage to other amino acids such as 
Trp and Met predominate in Mb products [21]. Thus, it is possible that Trp and Met oxidation also play a more significant role in altering $\mathrm{Mb}$ peroxidase activity, possibly through alterations in protein tertiary structure, and this may have pathophysiological implications considering that at least these same methionine oxidation products are detected in the myocardium following experimental heart attack [30]. Other possibilities include oxidation of amino acid residues that impact on protein structure causing (i) altered haem-iron reactivity to added $\mathrm{H}_{2} \mathrm{O}_{2}$ due to changes in the hydrogen bonding network within the active site cavity or (ii) changes to the redox activity of the haem-iron centre as a result of altered interactions between the haem prosthetic group yielding changes to conformational binding of the iron atom that impact the redox potential for the Fe-centre. Notably, distal-H bonding effects between amino acids within the protein and the haem-centre in the active site are known to regulate haem-iron redox characteristics and ligand binding [41] and previous studies using site-directed mutation of histidine residues in the active site are known to alter $\mathrm{Mb}$ peroxidase activity [42]. Therefore, despite no direct evidence for altered histidine in $\mathrm{HOCl}$-oxidized $\mathrm{hhMb}$, oxidative modifications to other redox sensitive amino acids in $\mathrm{hhMb}$ may well be responsible for changing distal-H bonding effects in the protein as manifested here by the altered electronic spectral features for HOCl-modified hhMb [43] and decreased peroxidase activity demonstrated by the inhibition of ABTS oxidation (Figure 6).

The catalase-like antioxidant activity of haem peroxidase proteins is known to occur through a mechanism that involves the intermediates that are formed when a professional peroxidase enzyme reacts with $\mathrm{H}_{2} \mathrm{O}_{2}$ [14]. This catalase mimetic activity is further limited by the presence of a suitable electron-donating substrate as this promotes the peroxidase pathway in favor of $\mathrm{H}_{2} \mathrm{O}_{2}$ degradation. In the absence of a suitable reductant $\mathrm{Mb}$-mediated $\mathrm{H}_{2} \mathrm{O}_{2}$ degradation involves formation of $\mathrm{MbFe}(\mathrm{IV})=\mathrm{O}^{+} / \mathrm{Mb}$ compound I (Equation (1)) and a subsequent oxidation reaction between $\mathrm{MbFe}(\mathrm{IV})=\mathrm{O}^{+} \bullet / \mathrm{Mb}$ compound I and peroxide that recycles $\mathrm{MbFe}(\mathrm{III})$ and yields water and molecular oxygen (Equation (2)); this is the rate limiting step in this catalase-like activity [44]. Interestingly, point mutations of histidine 93 in human $\mathrm{Mb}$ [45] or histidine 64 in other mammalian $\mathrm{Mb}$ [46] are known to stabilize $\mathrm{MbFe}(\mathrm{IV})=\mathrm{O}^{+\bullet}$ and enhance $\mathrm{Mb}$ catalase-like antioxidant activity.

$$
\begin{gathered}
\mathrm{MbFe}(\mathrm{III})+\mathrm{H}_{2} \mathrm{O}_{2} \rightarrow \mathrm{MbFe}(\mathrm{IV})=\mathrm{O}^{+\bullet}+\mathrm{H}_{2} \mathrm{O} \\
\mathrm{MbFe}(\mathrm{IV})=\mathrm{O}^{+\bullet}+\mathrm{H}_{2} \mathrm{O}_{2} \rightarrow \mathrm{MbFe}(\mathrm{III})+\mathrm{H}_{2} \mathrm{O}+\mathrm{O}_{2}
\end{gathered}
$$

By comparison our data likely indicate that stabilization of $\mathrm{MbFe}(\mathrm{IV})=\mathrm{O}^{+\bullet}$ in $\mathrm{HOCl}$-oxidized $\mathrm{hhMb}$ (through a mechanism involving inhibited intra-molecular translocation of the radical cation from $\mathrm{MbFe}(\mathrm{IV})=\mathrm{O}^{+} \bullet / \mathrm{Mb}$ compound I to the protein backbone through chemical reduction by redox active amino acids; Figure 5) has no meaningful effect on $\mathrm{Mb}$ catalase-like antioxidant activity with the extent of peroxide degradation being the same for both native (in the absence of $\mathrm{HOCl}$-treatment) and $\mathrm{HOCl}$-modified $\mathrm{hhMb}$ (up to $\mathrm{HOCl} / \mathrm{hhMb}=20 \mathrm{~mol} / \mathrm{mol}$; Figure $6 \mathrm{~A}$ ). Maintenance of the catalase-like antioxidant activity is contrasted by a marked decrease in pseudoperoxidase activity of HOCl-modified $\mathrm{hhMb}$, which indicates that reaction of $\mathrm{MbFe}(\mathrm{IV})=\mathrm{O}^{+\bullet}$ and the exogenous substrate ABTS occurs with a lower rate constant, possibly reflecting a lower absolute concentration of $\mathrm{MbFe}(\mathrm{IV})=\mathrm{O}^{+} \boldsymbol{\bullet}$ as a consequence of $\mathrm{HOCl}$-oxidation of the protein. Overall, the high concentration of $\mathrm{Mb}$ in cardiac tissues suggests that this haem protein may complement endogenous catalase in degrading excessive $\mathrm{H}_{2} \mathrm{O}_{2}$, particularly during AMI where hypoxic insult coupled with reoxygenation injury results in acute peroxide production. Therefore, the ability for $\mathrm{HOCl}$-oxidized $\mathrm{Mb}$ to maintain catalase-like antioxidant activity may allow cardiac myoglobin to continue to degrade accumulating $\mathrm{H}_{2} \mathrm{O}_{2}$ under conditions where $\mathrm{HOCl}$ are also produced in high concentration post AMI, thereby inhibiting ongoing oxidative stress in the affected myocardium upon resumption of blood flow (and thereby, limiting reperfusion injury).

Exposure of ferric hhMb to regent $\mathrm{HOCl}$ alters the ferric-to-ferrous haem reduction by a cytochrome $b 5$ reductase system [15], which is considered the most likely intercellular reductase system responsible for maintaining the ferrous $\mathrm{Mb}$ form suitable for intracellular oxygen binding and storage [26]. 
Previously we reported that reagent $\mathrm{HOCl}$ oxidized several residues in human myoglobin resulting in decreased rates of $\mathrm{MbFe}(\mathrm{III})$ reduction with cytochrome $b 5$ reductase [35] and herein we recapitulate this outcome with $\mathrm{hhMb}$ and demonstrate a similar reagent $\mathrm{HOCl}$ dose-dependent decrease in the rate of one-electron reduction of ferric $\mathrm{hhMb}$ by the MetMb reductase system. As such, interruption of ferric-to-ferrous recycling decreases the potential for $\mathrm{Mb}$ to continue efficient oxygen transport to mitochondria [47] since $\mathrm{MbFe}(\mathrm{III})$ is unable to bind to molecular oxygen. Myoglobin is essential for oxygen supply [48] therefore decreased ATP production as a result of decreased oxygen supply, disrupts the active $\mathrm{Na}^{+}-\mathrm{K}^{+}$-ATPase pump leading to alterations in the level of sodium ions [49], which in turn stimulates the release of calcium ions through the activity of the membrane sodium-calcium exchanger transporter. Excessive calcium levels further damage mitochondria and render the cell more susceptible to oxidative damage and apoptosis, which are all hall marks of the necrotic myocardium post-AMI and other pathologies where $\mathrm{Mb}$ is implicated such as rhabdomyolysis-mediated renal damage [50].

Mammalian $\mathrm{Mb}$ also displays other functions such as nitrate reductase [51] and lipid metabolism activities [52]. Whether $\mathrm{HOCl}$ modification of $\mathrm{Mb}$ impacts these other functions is not clear. However, if found to be true this would suggest that $\mathrm{HOCl}$-mediated changes to $\mathrm{Mb}$ function may have wide ranging pathophysiological impact, especially in tissues where $\mathrm{Mb}$ is found in relatively high concentration, such as the heart. For example, under physiological conditions, $\mathrm{Mb}$ acts as a NO scavenger thereby limiting its damaging effect on mitochondrial respiration however in ischemic conditions such as post myocardial infarction, $\mathrm{Mb}$ is capable of generating $\mathrm{NO}$ with the potential to promote vasodilation of blood vessels thereby increasing oxygen supply to affected myocytes [53]. Furthermore, increased NO production in the myocardium after AMI inhibits mitochondrial complex I known to generate reactive oxygen species post reperfusion. Notably, $\mathrm{NO}$ also inhibits the opening of the mitochondrial permeability transition pore involved in cytochrome $c$ release and apoptosis post reperfusion [54]. Thus, functional $\mathrm{Mb}$ may be critical to the recovery of the damaged myocardium post-AMI by acting through multiple pathways involving different activities where oxygen binding to $\mathrm{MbFe}(\mathrm{II})$ is central to maintenance of those activities. Through altering $\mathrm{Mb}$ function, neutrophil-HOCl may then promote further damage to the myocardium following AMI and this may be linked to longer-term cardiac disorders such as heart failure.

\section{Conclusions}

The present study has documented that reagent $\mathrm{HOCl}$ is capable of promoting post-translational changes to $\mathrm{hhMb}$ that impact selected biochemical activities of the protein. The post-translational changes detected in hhMb (here) closely mimic post-translational modification previously determined for horse [21] and human [34] Mb indicating that these changes are likely to be common amongst mammalian Mbs with similar protein sequences. Furthermore, as we have previously described for human $\mathrm{Mb}$, HOCl-modified hhMbFe(III) exhibits decreased one-electron reduction to the $\mathrm{MbFe}(\mathrm{II})$ form that diminishes the capacity for oxygen binding/transport. This present study expands on this knowledge base and now shows that $\mathrm{Mb}$ catalase-like activity is maintained even in the presence of $\mathrm{HOCl}$ at an oxidant:protein ratio up to $20 \mathrm{~mol} / \mathrm{mol}$. However, this is not the case for $\mathrm{Mb}$ pseudo-peroxidase activity, which was demonstrated here to be inhibited by HOCl-mediated post-translational modification. Therefore, $\mathrm{Mb}$ catalase-like activity will act in concert with native catalase to neutralize excessive $\mathrm{H}_{2} \mathrm{O}_{2}$ thus minimizing the damage to cardiomyocytes. If peroxide overwhelms the compensatory catalase like activity of $\mathrm{Mb}$ then suppression of the peroxidase activity may be important as peroxidase enzymatic cycling can cause oxidation of a range of biological targets including aromatic substrates/antioxidants/redox sensitive thiols thereby impacting the physiological levels of these biomolecules. The potential for $\mathrm{HOCl}$-oxidized $\mathrm{Mb}$ to potentiate cardiac damage under these conditions warrants further investigation in animal models of heart attack where at least some of these post-translationally modified $\mathrm{Mb}$ oxidation products have been previously detected [30]. 
Author Contributions: Conceptualization: P.K.W., B.C.; methodology: G.A., B.C., M.E.K., X.W., M.T.S.M., N.H., A.M.M., T.W.H.; formal analysis: G.A., B.C., N.H., M.T.S.M., X.W., A.M.M., T.W.H.; investigation: G.A., M.E.K., B.C., N.H., M.T.S.M.; data curation: G.A., N.H., M.T.S.M., B.C., P.K.W.; writing - original draft preparation: G.A., M.E.K. and P.K.W.; writing - review \& editing: G.A., B.C., X.W., P.K.W.; Supervision: P.K.W.

Funding: The authors acknowledge funding from the Australian Research Council (grant DP130103711) and the NHMRC Project grant (APP1125392).

Acknowledgments: We thank the Bosch Institute for providing shared facilities for Mass Spectrometry to conduct part to the research herein. We acknowledge the assistance from the Brazilian Government Science Without Borders Scheme that funded Moreira for a 6-month interlaboratory exchange in the Redox Biology Group at the Charles Perkins Centre, The University of Sydney.

Conflicts of Interest: The authors declare no conflict of interest. Also, the funding agencies had no role in the design of the study; in the collection, analyses, or interpretation of data; in the writing of the manuscript, or in the decision to publish the results.

\section{References}

1. Bonaventura, A.; Montecucco, F.; Dallegri, F. Cellular recruitment in myocardial ischaemia/reperfusion injury. Eur. J. Clin. Investig. 2016, 46, 590-601. [CrossRef] [PubMed]

2. Dirksen, M.T.; Simoons, M.L.; Duncker, D.J.; Laarman, G.J. Reperfusion injury in humans: A review of clinical trials on reperfusion injury inhibitory strategies. Cardiovasc. Res. 2007, 74, 343-355. [CrossRef] [PubMed]

3. Davies, M.J. Myeloperoxidase-derived oxidation: Mechanisms of biological damage and its prevention. J. Clin. Biochem. Nutr. 2011, 48, 8-19. [CrossRef] [PubMed]

4. Carr, A.C.; Winterbourn, C.C. Oxidation of neutrophil glutathione and protein thiols by myeloperoxidase-derived hypochlorous acid. Biochem. J. 1997, 327, 275-281. [CrossRef] [PubMed]

5. Pattison, D.; Davies, M. Reactions of Myeloperoxidase-Derived Oxidants with Biological Substrates: Gaining Chemical Insight into Human Inflammatory Diseases. Curr. Med. Chem. 2006, 13, 3271-3290. [CrossRef] [PubMed]

6. Arnhold, J.; Hammerschmidt, S.; Wagner, M.; Mueller, S.; Arnold, K.; Grimm, E. On the action of hypochlorite on human serum albumin. Biomed. Biochim. Acta 1990, 49, 991-997.

7. Wittenberg, B.A.; Wittenberg, J.B. Transport of oxygen in muscle. Annu. Rev. Physiol. 1989, 51, 857-878. [CrossRef]

8. Raschke, P.; Becker, B.F.; Leipert, B.; Schwartz, L.M.; Zahler, S.; Gerlach, E. Postischemic dysfunction of the heart induced by small numbers of neutrophils via formation of hypochlorous acid. Basic Res. Cardiol. 1993, 88, 321-339.

9. Wittenberg, J.B. Myoglobin-facilitated oxygen diffusion: Role of myoglobin in oxygen entry into muscle. Physiol. Rev. 1970, 50, 559-636. [CrossRef]

10. Wittenberg, J.B.; Wittenberg, B.A. Myoglobin function reassessed. J. Exp. Biol. 2003, 206, 2011-2020. [CrossRef]

11. Brunori, M. Nitric oxide moves myoglobin centre stage. Trends Biochem. Sci. 2001, 26, 209-210. [CrossRef]

12. Shiva, S.; Huang, Z.; Grubina, R.; Sun, J.; Ringwood, L.A.; MacArthur, P.H.; Xu, X.; Murphy, E.; Darley-Usmar, V.M.; Gladwin, M.T. Deoxymyoglobin Is a Nitrite Reductase That Generates Nitric Oxide and Regulates Mitochondrial Respiration. Circ. Res. 2007, 100, 654-661. [CrossRef] [PubMed]

13. Dungel, P.; Penzenstadler, C.; Ashmwe, M.; Dumitrescu, S.; Stoegerer, T.; Redl, H.; Bahrami, S.; Kozlov, A.V. Impact of mitochondrial nitrite reductase on hemodynamics and myocardial contractility. Sci. Rep. 2017, 7, 12092. [CrossRef] [PubMed]

14. Vlasits, J.; Jakopitsch, C.; Bernroitner, M.; Zamocky, M.; Furtmüller, P.G.; Obinger, C. Mechanisms of catalase activity of heme peroxidases. Arch. Biochem. Biophys. 2010, 500, 74-81. [CrossRef] [PubMed]

15. Hagler, L.; Coppes, R.; Herman, R.H. Metmyoglobin reductase. Identification and purification of a reduced nicotinamide adenine dinucleotide-dependent enzyme from bovine heart which reduces metmyoglobin. J. Biol. Chem. 1979, 254, 6505-6514.

16. Witting, P.K.; Wu, B.J.; Raftery, M.; Southwell-Keely, P.; Stocker, R. Probucol protects against hypochlorite-induced endothelial dysfunction: Identification of a novel pathway of probucol oxidation to a biologically active intermediate. J. Biol. Chem. 2005, 280, 15612-15618. [CrossRef] [PubMed] 
17. Witting, P.K.; Willhite, C.; Davies, M.J.; Stocker, R. Lipid oxidation in human low-density lipoprotein induced by metmyoglobin/H2O2: Involvement of alpha-tocopheroxyl and phosphatidylcholine alkoxyl radicals. Chem. Res. Toxicol. 1999, 12, 1173-1181. [CrossRef]

18. Sparks, D.L.; Phillips, M.C. Quantitative measurement of lipoprotein surface charge by agarose gel electrophoresis. J. Lipid Res. 1992, 33, 123-130.

19. Hawkins, C.L.; Morgan, P.E.; Davies, M.J. Quantification of protein modification by oxidants. Free Radic. Biol. Med. 2009, 46, 965-988. [CrossRef]

20. Shanu, A.; Groebler, L.; Kim, H.B.; Wood, S.; Weekley, C.M.; Aitken, J.B.; Harris, H.H.; Witting, P.K. Selenium Inhibits Renal Oxidation and Inflammation But Not Acute Kidney Injury in an Animal Model of Rhabdomyolysis. Antioxid. Redox Signal. 2013, 18, 756-769. [CrossRef]

21. Szuchman-Sapir, A.J.; Pattison, D.I.; Ellis, N.A.; Hawkins, C.L.; Davies, M.J.; Witting, P.K. Hypochlorous acid oxidizes methionine and tryptophan residues in myoglobin. Free Radic. Biol. Med. 2008, 45, 789-798. [CrossRef] [PubMed]

22. Witting, P.K.; Mauk, A.G.; Lay, P.A. Role of Tyrosine-103 in Myoglobin Peroxidase Activity: Kinetic and Steady-State Studies on the Reaction of Wild-Type and Variant Recombinant Human Myoglobins with H2O2. Biochemistry 2002, 41, 11495-11503. [CrossRef] [PubMed]

23. Kotake, Y.; Reinke, L.A.; Tanigawa, T.; Koshida, H. Determination of the rate of superoxide generation from biological systems by spin trapping: Use of rapid oxygen depletion to measure the decay rate of spin adducts. Free Radic. Biol. Med. 1994, 17, 215-223. [CrossRef]

24. Cho, Y.S.; Kim, H.S.; Kim, C.H.; Cheon, H.G. Application of the ferrous oxidation-xylenol orange assay for the screening of 5-lipoxygenase inhibitors. Anal. Biochem. 2006, 351, 62-68. [CrossRef] [PubMed]

25. Kuma, F. Properties of methemoglobin reductase and kinetic study of methemoglobin reduction. J. Biol. Chem. 1981, 256, 5518-5523. [PubMed]

26. Livingston, D.J.; McLachlan, S.J.; La Mar, G.N.; Brown, W.D. Myoglobin: Cytochrome b5 interactions and the kinetic mechanism of metmyoglobin reductase. J. Biol. Chem. 1985, 260, 15699-15707. [PubMed]

27. Charlton, T.S.; Domigan, N.M.; Duncan, M.W.; Winterbourn, C.C.; Kettle, A.J. Chlorination of Tyrosyl Residues in Peptides by Myeloperoxidase and Human Neutrophils. J. Biol. Chem. 1995, 270, 16542-16548.

28. Zaia, J.; Annan, R.S.; Biemann, K. The correct molecular weight of myoglobin, a common calibrant for mass spectrometry. Rapid Commun. Mass Spectrom. 1992, 6, 32-36. [CrossRef]

29. Manzanares, D.; Rodríguez-Capote, K.; Liu, S.; Haines, T.; Ramos, Y.; Zhao, L.; Doherty-Kirby, A.; Lajoie, G.; Possmayer, F. Modification of Tryptophan and Methionine Residues Is Implicated in the Oxidative Inactivation of Surfactant Protein B. Biochemistry 2007, 46, 5604-5615. [CrossRef]

30. Wang, X.S.; Kim, H.B.; Szuchman-Sapir, A.; McMahon, A.; Dennis, J.M.; Witting, P.K. Neutrophils recruited to the myocardium after acute experimental myocardial infarct generate hypochlorous acid that oxidizes cardiac myoglobin. Arch. Biochem. Biophys. 2016, 612, 103-114. [CrossRef]

31. Gunther, M.R.; Tschirret-Guth, R.; Witkowska, H.; Fann, Y.C.; Barr, D.P.; De Montellano, P.R.O.; Mason, R.P. Site-specific spin trapping of tyrosine radicals in the oxidation of metmyoglobin by hydrogen peroxide. Biochem. J. 1998, 330, 1293-1299. [CrossRef] [PubMed]

32. Degray, J.; Gunther, M.R.; Tschirret-Guth, R.; De Montellano, P.R.O.; Mason, R.P. Peroxidation of a specific tryptophan of metmyoglobin by hydrogen peroxide. J. Biol. Chem. 1997, 272, 2359-2362. [CrossRef] [PubMed]

33. Davies, M.J. Identification of a globin free radical in equine myoglobin treated with peroxides. Biochim. Biophys. Acta Protein Struct. Mol. Enzym. 1991, 1077, 86-90. [CrossRef]

34. Irwin, J.A.; Østdal, H.; Davies, M.J. Myoglobin-Induced Oxidative Damage: Evidence for Radical Transfer from Oxidized Myoglobin to Other Proteins and Antioxidants. Arch. Biochem. Biophys. 1999, 362, 94-104. [CrossRef] [PubMed]

35. Szuchman-Sapir, A.J.; Pattison, D.I.; Davies, M.J.; Witting, P.K. Site-specific hypochlorous acid-induced oxidation of recombinant human myoglobin affects specific amino acid residues and the rate of cytochrome b5-mediated heme reduction. Free Radic. Biol. Med. 2010, 48, 35-46. [CrossRef] [PubMed]

36. Lardinois, O.M.; De Montellano, P.R.O. Autoreduction of Ferryl Myoglobin: Discrimination among the Three Tyrosine and Two Tryptophan Residues as Electron Donors. Biochemistry 2004, 43, 4601-4610. [CrossRef] [PubMed] 
37. Gunther, M.R.; Sturgeon, B.E.; Mason, R.P. A long-lived tyrosyl radical from the reaction between horse metmyoglobin and hydrogen peroxide. Free Radic. Biol. Med. 2000, 28, 709-719. [CrossRef]

38. Catalano, C.; Choe, Y.S.; De Montellano, P.R.O. Reactions of the protein radical in peroxide-treated myoglobin. Formation of a heme-protein cross-link. J. Biol. Chem. 1989, 264, 10534-10541.

39. Veitch, N.C. Horseradish peroxidase: A modern view of a classic enzyme. Phytochemistry 2004, 65, 249-259. [CrossRef]

40. Dunford, H.B. Horseradish peroxidase: Structure and kinetic properties. In Peroxidases in Chemistry and Biology; Everse, K.E., Grisham, M.B., Eds.; CRC Press: Boca Raton, FL, USA, 1991; Volume 2.

41. Watanabe, M.; Kanai, Y.; Nakamura, S.; Nishimura, R.; Shibata, T.; Momotake, A.; Yanagisawa, S.; Ogura, T.; Matsuo, T.; Hirota, S.; et al. Synergistic Effect of Distal Polar Interactions in Myoglobin and Their Structural Consequences. Inorg. Chem. 2018, 57, 14269-14279. [CrossRef]

42. Ozaki, S.-I.; Roach, M.P.; Matsui, T.; Watanabe, Y. Investigations of the Roles of the Distal Heme Environment and the Proximal Heme Iron Ligand in Peroxide Activation by Heme Enzymes via Molecular Engineering of Myoglobin. Acc. Chem. Res. 2001, 34, 818-825. [CrossRef]

43. Kanai, Y.; Nishimura, R.; Nishiyama, K.; Shibata, T.; Yanagisawa, S.; Ogura, T.; Matsuo, T.; Hirota, S.; Neya, S.; Suzuki, A.; et al. Effects of Heme Electronic Structure and Distal Polar Interaction on Functional and Vibrational Properties of Myoglobin. Inorg. Chem. 2016, 55, 1613-1622. [CrossRef] [PubMed]

44. Krishna, M.C.; Samuni, A.; Taira, J.; Goldstein, S.; Mitchell, J.B.; Russo, A. Stimulation by nitroxides of catalase-like activity of hemeproteins. Kinetics and mechanism. J. Biol. Chem. 1996, 271, 26018-26025. [CrossRef] [PubMed]

45. Adachi, S.; Nagano, S.; Ishimori, K.; Watanabe, Y.; Morishima, I.; Egawa, T.; Kitagawa, T.; Makino, R. Roles of proximal ligand in heme proteins: Replacement of proximal histidine of human myoglobin with cysteine and tyrosine by site-directed mutagenesis as models for P-450, chloroperoxidase, and catalase. Biochemistry 1993, 32, 241-252. [CrossRef] [PubMed]

46. Kato, S.; Ueno, T.; Fukuzumi, S.; Watanabe, Y. Catalase reaction by myoglobin mutants and native catalase: Mechanistic investigation by kinetic isotope effect. J. Biol. Chem. 2004, 279, 52376-52381. [CrossRef] [PubMed]

47. Marzouki, L.; Jarry, G.; Janati-Idrissi, R.; Amri, M. The Role of Myoglobin in Retarding Oxygen Depletion in Anoxic Heart. Arch. Physiol. Biochem. 2002, 110, 400-407. [CrossRef] [PubMed]

48. Gödecke, A.; Flögel, U.; Zanger, K.; Ding, Z.; Hirchenhain, J.; Decking, U.K.M.; Schrader, J. Disruption of myoglobin in mice induces multiple compensatory mechanisms. Proc. Natl. Acad. Sci. USA 1999, 96, 10495-10500. [CrossRef]

49. Boldyrev, A.A. Functional activity of $\mathrm{Na}+, \mathrm{K}(+)$-pump in normal and pathological tissues. Mol. Chem. Neuropathol. 1993, 19, 83-93. [CrossRef]

50. Reeder, B.J.; Svistunenko, D.A.; Cooper, C.E.; Wilson, M.T. The Radical and Redox Chemistry of Myoglobin and Hemoglobin: From In Vitro Studies to Human Pathology. Antioxid. Redox Signal. 2004, 6, 954-966.

51. Hendgen-Cotta, U.B.; Merx, M.W.; Shiva, S.; Schmitz, J.; Becher, S.; Klare, J.P.; Steinhoff, H.-J.; Goedecke, A.; Schrader, J.; Gladwin, M.T.; et al. Nitrite reductase activity of myoglobin regulates respiration and cellular viability in myocardial ischemia-reperfusion injury. Proc. Natl. Acad. Sci. USA 2008, 105, 10256-10261. [CrossRef]

52. Hendgen-Cotta, U.B.; Esfeld, S.; Coman, C.; Ahrends, R.; Klein-Hitpass, L.; Flögel, U.; Rassaf, T.; Totzeck, M. A novel physiological role for cardiac myoglobin in lipid metabolism. Sci. Rep. 2017, 7, 43219. [CrossRef] [PubMed]

53. Totzeck, M.; Hendgen-Cotta, U.B.; Luedike, P.; Berenbrink, M.; Klare, J.P.; Steinhoff, H.-J.; Semmler, D.; Shiva, S.; Williams, D.; Kipar, A.; et al. Nitrite Regulates Hypoxic Vasodilation via Myoglobin-Dependent Nitric Oxide Generation. Circulation 2012, 126, 325-334. [CrossRef] [PubMed]

54. Brookes, P.S.; Salinas, E.P.; Darley-Usmar, K.; Eiserich, J.P.; Freeman, B.A.; Darley-Usmar, V.M.; Anderson, P.G. Concentration-dependent Effects of Nitric Oxide on Mitochondrial Permeability Transition and Cytochrome cRelease. J. Biol. Chem. 2000, 275, 20474-20479. [CrossRef] [PubMed]

(C) 2019 by the authors. Licensee MDPI, Basel, Switzerland. This article is an open access article distributed under the terms and conditions of the Creative Commons Attribution (CC BY) license (http://creativecommons.org/licenses/by/4.0/). 